\title{
MUGIDO, MUERTE Y MISTERIO: EL MITO DE RULFO
}

\section{Por \\ CARLOS FUENTES}

A la mitad exacta del Pedro Páramo de Juan Rulfo se escucha el mugido de una vaca. Fulgor Sedano, el brazo armado del cacique, da órdenes a los vaqueros de aventar el ganado de Enmedio más allá de lo que fue Estagua, y de correr el de Estagua para los cerros de Vilmayo. "¡Y apriétenle-terminaque ya se nos vienen las aguas!".

Apenas sale el último hombre a los campos lluviosos, entra a todo galope Miguel Páramo, el hijo consentido del cacique, se apea del caballo casi en las narices de Fulgor y deja que el caballo busque solo su pesebre.

"—De dónde vienes a estas horas, muchacho?, le pregunta Sedano.

"-Vengo de ordeñar", contesta Miguel y en seguida, en la cocina mientras le prepara sus huevos, le contesta a Damiana que llega de por ahi de visitar madres. Y pide que se le dé de comer igual que a él a una mujer que está allá afuerita, con un molote en su rebozo que arrulla diciendo que es su crío.

"- Parece ser que le sucedió alguna desgracia allá en sus tiempos, pero, como nunca habla, nadie sabe lo que le pasó. Vive de limosna."

Mugir, ordeñar, parir, arrullar: en silencio, de limosna, porque sufrimos una desgracia allá en otros tiempos.

Quisiera recordar este centro deceptivamente simple de la novela de Rulfo, antes de adentrarme en su impresionante y compleja estructura multiintencional. Esta se presenta ritualmente con un elemento clásico del mito: la búsqueda del padre. Juan Preciado, el hijo de Pedro Páramo, llega a Comala: como Telémaco, busca a Ulises. Un arriero llamado Abundio lo conduce. El Caronte y el Estigio que ambos cruzan es un río de polvo. Abundio se revela como hijo de Pedro Páramo y abandona a Juan Preciado en la boca del infierno de Comala. Juan Preciado asume el mito de Orfeo: va a contar y va a cantar mientras desciende al infierno, pero a condición de no mirar hacia atrás. Lo guía la voz de su madre, Doloritas, la Penélope humillada del Ulises de barro, Pedro Páramo. Pero esa voz se vuelve cada vez más tenue: Orfeo no puede mirar hacia atrás y, esta vez, desconoce a Eurídice: no son esta sucesión de mujeres que suplantan a la madre y que más bien parecen Virgilios con faldas: Eduviges, Damiana, Dorotea la Cuarraca con su molote arrullado. 
Son ellas quienes introducen a Juan Preciado en el pasado de Pedro Páramo: un pasado contiguo, adyacente, como el imaginado por Coleridge: no atrás, sino al lado, detrás de esa puerta, al abrir esa ventana. Así, al lado de Juan reunido con Eduviges en un cuartucho de Comala está el niño Pedro Páramo en el excusado, recordando a una tal Susana. No sabemos que está muerto; podemos suponer que sueña de niño a la mujer que amará de grande.

Eduviges está con el joven Juan al lado de la historia del joven Pedro: le revela que iba a ser su madre y oye el caballo de otro hijo de Pedro Páramo, Miguel, que se acerca a contarnos su muerte. Pero al lado de esta historia, de esta muerte, está presente otra: la muerte del padre de Pedro Páramo.

Eduviges le ha preguntado a Juan en la página 27:

“- ¿Has oído alguna vez el quejido de un muerto?

"-No, doña Eduviges.

"-Más te vale," contesta la vieja.

Este diálogo es retomado en la página 36:

"-Más te vale, hijo, Más te vale".

Pero entre los dos diálogos de Eduviges, que son el mismo diálogo en el mismo instante, palabras idénticas a sí mismas y a su momento, palabras espejo, ha muerto el padre de Pedro Páramo, ha muerto Miguel el hijo de Pedro Páramo, el padre Rentería se ha negado a bendecir el cadáver de Miguel, el fantasma de Miguel ha visitado a su amante Ana, la sobrina del señor cura, y éste sufre remordimientos de conciencia que le impiden dormir. Hay más: la propia mujer que habla, Eduviges Dyada, en el acto de hablar y mientras todo esto ocurre contiguamente, se revela como un ánima en pena y Juan Preciado es recogido por su nueva madre sustituta, la nana Damiana Cisneros.

Tenemos pues dos órdenes primeros de la estructura literaria en Pedro Páramo: una realidad dada y el movimiento de esa realidad. Los segmentos dados de la realidad son cualesquiera de los que he mencionado: Rentería se niega a enterrar a Miguel, el niño Pedro sueña con Susana encerrado en el baño, muere el padre de Pedro, Juan Preciado llega a Comala, Eduviges desaparece y la sustituye Damiana.

Pero esos segmentos sólo tienen realidad en el movimiento narrativo, en el roce con lo que les sigue o precede, en la yuxtaposición del tiempo de cada segmento con los tiempos de los demás segmentos. Cuando el tiempo de unas palabras-Más te vale hijo, más te vale-retorna nueve páginas después de ser pronunciadas, entendemos que esas palabras no están separadas por el tiempo, sino que son instantáneas y sólo instantá neas; no ha ocurrido nada entre la página 27 y la página 36 . 0 más bien: cuanto ha ocurrido ha ocurrido simultáneamente. 
Apenas entendemos que los tiempos de Pedro Páramo son tiempos simultáneos, comenzamos a acumular y a yuxtaponer, retroactivamente, esta contigüidad de los tiempos que vamos conociendo. La historia de Pedro Páramo que le cuentan a Juan sus madres sucesivas es una historia política y sicológica "realista". Pedro Páramo es la versión jaliscience del tirano patrimonial cuyo retrato hemos evocado en las novelas de Valle Inclán, Gallegos y Asturias: el mini-César que manipula todas las fuerzas políticas pero al mismo tiempo debe hacerles concesiones; el Príncipe agrario que, no sin grandeza, se hace eco de la hermosa frase de Maquiavelo:

"Dios no lo hará todo, pues esto nos despojaría de nuestro libre albed río y de la parcela de gloria que nos pertenece".

Maquiavelo es el hermano de los conquistadores del Nuevo Mundo; $E l$ Principe es un elogio de la voluntad y una condenación de la providencia; es el manual para el hombre nuevo del Renacimiento que se propone ser el gobernante nuevo, sin herencias que dependan de la veleidosa Fortuna. Descendiente de los conquistadores de la Nueva Galicia, émulo feroz de Nuño de Guzmán, Pedro Páramo acumula todas las grandes lecciones de Maquiavelo, salvo una. Como el florentino, el jaliscience sabe que un príncipe sabio debe alimentar algunas animosidades contra él mismo, a fin de aumentar su grandeza cuando las venza; sabe que es mucho más seguro ser temido que ser amado. En los divertidos segmentos en los que Rulfo narra los tratos de Pedro Páramo con las fuerzas revolucionarias, el cacique de Comala procede como lo recomendó Maquiavelo y como lo hizo Cortés: une a los enemigos menos poderosos de tu enemigo poderoso; luego arruínalos a todos; luego usurpa el lugar de todos, amigos y enemigos, y no lo sueltes más. Maquiavelo, Cortés, Pedro Páramo: no está de más poseer una virtud verbal y también una mente capaz de cambiar rápidamente. Pedro Páramo, el conquistador, el príncipe: Comete las crueldades de un solo golpe; distribuye los beneficios uno por uno.

$\mathrm{Y}$ sin embargo, este héroe del maquiavelismo patrimonial del Nuevo Mundo, señor de horca y cuchillo, amo de vidas y haciendas, dueño de una voluntad que impera sobre la fortuna de los demás y apropia para su patrimonio privado todo cuanto pertenece al patrimonio público, este profeta armado del capricho y la crueldad impunes, rodeado de sus bandas de mayordomos ensangrentados, no aprendió la otra lección de Maquiavelo.

No basta imponer la voluntad; hay que evitar los vaivenes de la Fortuna, pues el príncipe que depende de ella, será arruinado por ella. Pedro Páramo no es Cortés, no es el Príncipe maquiavélico porque, finalmente, es un personaje de novela. Tiene una falla secreta, un resquicio por donde las recetas del poder se desangran inútilmente. La Fortuna de Pedro Páramo es una mujer, Susana San Juan, con la que soñó de niño, encerrado en el baño. 
La primera función de Susana San Juan, si retornamos de la frase retomada de Eduviges Dyada y a la razón de esta técnica, y si la acoplamos al tremendo aguafuerte político y sicológico del cacique rural que Rulfo acaba por ofrecernos, es la de ser soñada por un niño y la de abrir, en ese niño que va a ser el tirano Páramo, una ventana anímica que acabará por destruirlo. Si al final de la novela Pedro Páramo se desmorona como si fuera un montón de piedras, es porque la fisura de su alma fue abierta por el sueño infantil de Susana: a través del sueño, Pedro fue arrancado a su historia política, maquiavélica, patrimonial desde antes de vivirla, desde antes de serla.

Sin saberlo, ingresó desde niño al mito, a la simultaneidad de tiempos que rige el mundo de su novela. Ese tiempo simultáneo será su derrota porque, para ser el cacique total, Pedro Páramo no podía admitir heridas en su tiempo lineal, sucesivo, lógico.

Pero en el centro mismo de la novela hay un mugido: el silencio es roto por las voces que no entendemos, las voces mudas del ganado mugiente, de la vaca ordeñada, de la mujer parturienta, del niño que nace, del molote inánime que arrulla en su rebozo una mendiga. Este silencio es el de la etimología misma de la palabra mito: $m u$, nos dice Erich Mahler, imitación del sonido elemental, res, trueno, mugido, musitar, murmurar, murmullo, mutismo. De la misma raíz procede el verbo griego muein, cerrar, cerrar los ojos, de donde derivan misterio y mística, los ritos y las enseñanzas secretas.

Novela misteriosa, mística, musitante, murmurante, mugiente y muda, PEDRO PÁRAMO concentra así todas las sonoridades muertas del mito. Mito y Muerte: esas son las dos "emes" que coronan todas las demás antes de que las corone el nombre mismo de México: novela mexicana esencial, insuperada e insuperable, Pedro Páramo se resume en el espectro de nuestro país: un murmullo de polvo desde el otro lado del río de la muerte.

La novela, como Uds. saben, se llamó originalmente "Los murmullos" y Juan Preciado, al violar radicalmente las normas de su propia presentación narrativa para ingresar al mundo de los muẹrtos de Comala, dice:

“-Me mataron los murmullos".

Lo mató el silencio. Lo mató el misterio. Lo mató la muerte. Lo mató el mito de la muerte. Juan Preciado ingresa a Comala y al hacerlo ingresa al mito encarnando el proceso lingüístico descrito por Kahler y que consiste en dar a una palabra el significado opuesto: como el "mutus" latín, mudo, se transforma en el "mot" francés, palabra, la onomatopeya $m u$, el sonido inarticulado, el mugido, se convierte en mythos la definición misma de la palabra.

Pedro Páramo es una novela extraordinaria, entre otras cosas, porque se genera a sí misma, como novela mítica, de la misma manera que el mito se 
genera verbalmente: del mutismo de la nada a la identificación con la palabra, de $m u$ a mythos y dentro del proceso colectivo que es indispensable a la gestación mítica, que nunca es un desarrollo individual. El acto, explica Hegel, es la épica. Pedro Páramo, el personaje, es un carácter de epopeya. Su novela, la que lleva su nombre, es un mito que despoja al personaje de su carácter épico.

Cuando Juan Preciado es vencido por los murmullos, la narración deja de hablar en primera persona y asume una tercera persona colectiva: de allí en adelante, es el nosotros el que habla, el que reclama el mythos de la obra.

En la antigüedad el mito nutre a la épica y a la tragedia. Es decir: las precede en el tiempo. Pero también en el lenguaje, puesto que el mito ilustra históricamente el paso del silencio--mudo-a la palabra-mythos-.

La precedencia en el tiempo-pero también la naturaleza colectiva-del mito es explicada por Carl Gustaf Jung cuando nos dice, en Los arquetipos del inconciente colectivo, que los mitos son revelaciones originales de la sique pre-conciente-declaraciones involuntarias acerca de eventos síquicos inconcientes. Los mitos, añade Jung, poseen un significado vital. No sólo la representan: son la vida síquica de la tribu, la cual inmediatamente cae hecha pedazos o decae cuando pierde su herencia mitológica, como un hombre que ha perdido su alma.

Recuerdo dos narraciones modernas que de manera ejemplar asumen esta actitud colectiva en virtud de la cual el mito no es inventado, sino vivido por todos: el cuento de William Faulkner, Una rosa para Emilia, y la novela de Juan Rulfo, Pedro Páramo. En estos dos relatos, el mito es la encarnación colectiva del tiempo, herencia de todos que debe ser mantenida, patéticamente, por todos, pues cabe distinguir dos niveles del universo mítico:

El primero es el del mito cosmogónico, celebración del origen, del nacimiento: Dios crea al mundo y éste es el primer mito.

El segundo es el mito post-cosmogónico, en el que la unidad primigenia se pierde al intervenir la historia. Esta pugna histórica puede manifestarse épicamente, como celebración del orden del poder humano, o trágicamente, como lamento de la pérdida de la unidad previa al poder. En todo caso, el mito post-cosmogónico requiere una representación; los dioses no repiten el acto de la creación; esta ausencia debe ser reparada por el acto humano representativo. Y este acto a menudo rebasa los límites del mito, su fijeza mortal en el origen, para reclamar la autoridad humana, rebelde y culpable cuando Prometeo desafía a Zeus, al nivel mítico, pero aceptable y heroica cuando Agamenón emplea el fuego de Prometeo contra los muros de Troya, al nivel épico pero trágica y dolorosa cuando Agamenón regresa a Argos y conoce en su hogar la falibilidad detrás de la coraza heroica, la fisura de la casa de Atreo. Las tumbas guardadas por Clitemnestra y Electra se llenan con la 
sangre de las trincheras de Troya y el silencio de la muerte vuelve a reinar, el mutismo original del mito, ansioso otra vez, como dice Hegel, de volver a ser mythos, palabra, vida.

En este alto nivel artístico se instala la novela Pedro Páramo. Mircea Eliade advierte que el sustrato mítico de la narrativa y de la historia es la evidencia de que el hombre no puede escapar al tiempo porque nunca hubo y nunca habrá un tiempo sin tiempo. Por ello, la función de la cultura mítica es hacer saber que el tiempo puede ser dominado, debe ser dominado si el tiempo primigenio, original, sin rupturas, ha de ser re-conquistado.

Re-conquistado, ¿por qué? Porque la memoria nos dice que entonces el hombre fue feliz. El arte cumple un vasto recorrido en busca de la tierra feliz del origen, de la isla de Nausicaa de Homero a la Edad de Oro de Luis Buñuel, pasando por el Paraíso cristiano de Dante y la Edad de Oro de Don Quijote. Pedro Páramo también contiene su antes feliz: la Comala descrita por la voz ausente de Doloritas, el murmullo de la madre:

"Un pueblo que huele a miel derramada".

Pero este pueblo frondoso que guarda nuestros recuerdos como un alcancía sólo puede ser recobrado en el recuerdo; es el "Edén subvertido" de López Velarde, creación histórica de la memoria pero también mito creado por el recuerdo. Hago la distinción griega entre mnemé, la memoria que es una técnica y es creada y la anamnésis, el recuerdo que es mítico y crea. Hay, pues, dos maneras de reconocer el pasado de Comala y Pedro Páramo.

Uno es el histórico y todas las explicaciones clásicas acerca de por qué se escribe la historia nos devuelven la idea de una estructura, de una cosa creada. Se trata para Herodoto de conservar la memoria de los actos de griegos y bárbaros, para Tucídides de ilustrar la lucha por el poder a fin de evitar que los errores se repitan, para Polibio de demostrar que toda la historia del mundo converge en Roma y para Livio de ofrecer modelos prácticos. Lección, legitimación, explicación, estructura, técnica.

En cambio, el mito tiene un carácter estructurante: estructurante, lo hemos visto, de la épica y de la tragedia; por ello, de la historia colectiva y de la individualidad. Estructurante, aun, de sí mismo y de otros mitos. El mito, indica Jung en sus Símbolos de transformación, es lo que es creído siempre, en todas partes y por todos. Por lo tanto, el hombre que cree que puede vivir sin el mito, o fuera de él, es una excepción. Es como un ser sin raíces, que carece del vínculo con el pasado, con la vida ancestral que sigue viviendo dentro de él, e incluso con la sociedad humana contemporánea. Como Pedro Páramo en sus últimos años, viejo e inmóvil en un equipal junto a la puerta grande de la Media Luna, esperando a Susana San Juan como Heathcliff esperó a Catherine Earnshaw en las Cumbres Borrascosas pero separado radicalmente 
de ella porque Susana pertenece al mundo mítico de la locura, la infancia, el erotismo y la muerte y Pedro pertenece al mundo histórico del poder, la conquista física de las cosas, la estrategia maquiavélica para subyugar a las personas y asemejarlas a las cosas.

Este hombre fuera del mito, añade Jung, no vive en una casa como los demás hombres, sino que vive una vida propia, hundida en una manía subjetiva de su propia hechura, que él considera como una verdad recién descubierta. La verdad recién descubierta de Pedro Páramo es la muerte, su deseo de reunirse con Susana- "No tarda ya. No tarda. Esta es mi muerte. Voy para allá. Ya voy"-. Muere una vez que ha dejado a Comala morirse, porque Comala convirtió en una feria la muerte de Susana San Juan:

"-Me cruzaré de brazos y Comala se morirá de hambre".

"Y así lo hizo".

Pedro Páramo, al condenar a muerte a Comala y sentarse en un equipal a esperar la suya, aparece como ese hombre sin mito del cual habla Jung: por más que la haya sufrido y por más que la haya dado, es un recién venido al reino de la muerte, que es parte de la realidad de la sique. Y la sique-prosigue Jung-no es algo de hoy: su genealogía se remonta a muchos millones de años. La conciencia individual es sólo la flor y el fruto de una temporada surgida del sustrato perenne debajo de la tierra.

Concluye Jung: La conciencia individual se encontraría en mejor armonía con la verdad si tomase en cuenta la existencia de este sustrato. "Pues la materia radical es la madre de todas las cosas".

Desde la perspectiva jungiana, es probable que Pedro Páramo, el hombre que no vive, come o bebe como los demás hombres, el hombre sin mito, sólo pueda reconocerse y reconocer a Comala como una ausencia por venir: la muerte está en el futuro, es un fin, nunca un comienzo. Se condena a muerte.

Pero para todos los demás, para ese coro de viejas nanas y señoritas abandonadas, brujas y limosneras, y sus pupilos fantasmales, los hijos de Pedro Páramo, Miguel y Abundio y Juan Preciado al cabo, la muerte está en el origen, se empieza con la muerte, lo primero que debemos recordar es la muerte:

"Alla me oirás mejor - dice la voz de Doloritas, la madre de Juan, mientras gúa a su hijo entre los murmullos de Comala-. Estaré más cerca de tí. Encontrarás más cercana la voz de mis recuerdos que la de mi muerte, si es que alguna vez la muerte ha tenido alguna voz".

En contra de Pedro Páramo, Comala sabe que estamos condenados a muerte. Pedro Páramo es en cierto modo una Telemaquia, la saga de la búsqueda y reunión con el padre. Pero como el padre está muerto-lo asesinó uno de los hijos, Abundio el arriero-buscar al padre y reunirse con él es 
buscar a la muerte y reunirse con ella. Esta novela es la historia de la entrada de Juan Preciado al reino de la muerte, no porque encontró la suya, sino porque la muerte lo encontró a él, lo hizo parte de su educación, le enseñó a hablar e identificó muerte y voces o, más bien, la muerte como un ansia de palabra, la palabra como eso que Villaurrutia llamó, certeramente, la nostalgia de la muerte.

Juan Preciado dice que los murmullos lo mataron: es decir, las palabras del silencio. "Mi cabeza venía llena de ruidos y de voces. De voces, sí. Y aquí donde el aire era escaso, se oían mejor. Se quedaban dentro de uno, pesadas".

Es la muerte la realidad que con mayor gravedad y tremor y ternura exige el lenguaje como prueba de su existencia. Quienes permanecen junto a las tumbas mientras los guerreros y los políticos actuán las hazañas de la epopeya lo saben: ¿no es Clitemnestra la única voz de su hija sacrificada, Ifigenia, en espera del regreso del padre, Agamenón, que la sacrificó? ¿no es Susana San Juan la única voz de su amante sacrificado, Florencio, en espera de la muerte del padre, Bartolomé, que lo sacrificó? Junto a las tumbas: cerca del mito. Rulfo va más lejos: dentro de las tumbas, lado a lado, diálogo de los muertos:

"-Siento como si alguien caminara sobre nosotros.

"- Ya déjate de miedos. Haz por pensar en cosas agradables porque vamos a estar mucho tiempo enterrados".

En Pedro Páramo el mito tiene la precedencia en el tiempo porque tiene la precedencia en la muerte. Por idéntica razón, tiene la precedencia en el lenguaje. "El mito es el nombre de cuanto existe, o subsiste", escribe Paul Valéry, "pero sólo en la medida en la que el habla es su causa". Suprema paradoja: nacido del mugido, del mutismo, el mito se convierte en identidad de la palabra. ¿Por qué? Porque es la primera identidad que adquiere la palabra y también la primera palabra que adquiere la identidad. Hay lenguaje antes de la épica y la tragedia; lo hay, sobra decirlo, antes de la novela, que es una lucha constante por revitalizar el lenguaje corriente, la moneda verbal de la calle: "La marquesa salió a las cinco de la tarde".

El mito es la identidad del lenguaje porque es la primera identidad con el lenguaje. Imaginemos el terror de dar voz por vez primera a los dioses: tal fue el pánico del mitólogo y seguramente pasaron siglos antes de que alguien se atreviese a rebasar el silencio para dar a conocer las divinas palabras. Hegel recuerda en la Estética que el oráculo griego de Dodona, intermediario de la voz de los dioses, no osaba manifestarse sino a través del suspiro agitado del castaño sagrado, el murmullo del arroyo o los tonos que el viento lograba arrancar a la vasija de bronce. El propio Apolo, dios de la sabiduría, sólo revelaba su voluntad a través de la voz indefinida de la Naturaleza, el sonido natural o los tonos inconexos de las palabras. 
Hay aquí un esfuerzo gigantesco y prolongado para llegar a identificar mito y palabra y, en su encuentro, mantener el recuerdo, la sique original de la tribu. El mito es la protohistoria, dice Gianbattista Vico, pero una vez inmersos en la historia, sólo a través del mito podemos reconocer de nuevo nuestra filiación, nuestra casa común.

La tierra de los muertos es el mito de Juan Rulfo y en él este autor crea y encuentra su arquetipo narrativo.

Para Jung, el arquetipo es el contenido del inconciente colectivo, y se manifiesta en dos movimientos: a partir de la madre, la matriz que le da forma; y a través del padre, el portador del arquetipo, su mitóforos. Desde esta ventana, podemos ver la novela de Rulfo como una visita a la tierra de la muerte que se sirve del conducto mítico supremo, el regreso al útero, a la madre que es recipiente del mito, fecundada por el mito - Doloritas y las madres sustitutas, Eduviges, Damiana, Dorotea-.

¿Hacia qué cosa nos conducen todas ellas junto con Juan Preciado? Hacia el portador del mito, el padre de la tribu, el ancestro maldito, Pedro Páramo, el fundador del Nuevo Mundo, el violador de las madres, el padre de todititos los hijos de la chingada.

Todas las parejas posibles e imposibles de la literatura que Julieta Campos enumera en su más reciente novela, de Orfeo y Eurídice a Hans Castorp y Claudia Chauchat, buscan salvarse juntos de la muerte y reconquistar el pasado idílico, el paraíso personal perdido. Pero aquí, ¿cómo reconstruir nada, a través de esta madre humillada y este padre cruel?, ¿cómo desalojar a la muerte con el odio, la venganza, el resentimiento y la humillación?

El desplazamiento de la promesa de vida y regeneración del mundo yermo de Pedro Páramo y Doloritas, los padres de Juan Preciado, al mundo erótico de Susana San Juan resulta imposible porque Susana pertenece al mito y Pedro Páramo a la épica, dijimos, Susana San Juan, protagonista de varios mitos entrecruzados - el incesto con su padre Bartolomé, la pareja idílica con su amante Florencio-es portadora de uno que los resume todos: el del eterno presente de la muerte. Enterrada en vida, habitante de un mundo que rechina, prisionera de una "sepultura de sábanas", Susana no hace ningún distingo entre lo que Pedro Páramo lla maría vida y lo que llamaría muerte: si ella tiene "la boca llena de tierra"es, al mismo tiempo, porque "tengo la boca llena de tí, de tu boca, Florencio".

Susana San Juan ama a un muerto: una muerta ama a un muerto. Y es ésta la puerta por donde Susana escapa al dominio de Pedro Páramo. Pues si el cacique tiene dominios, ella tiene demonios. Loco amor, lo lla maría Breton; loco amor de Pedro Páramo hacia Susana San Juan y loco amor de Susana San Juan hacia ese nombre de la muerte que es Florencio. Pero no loco amor de Susana $y$ Pedro. 
Por su clima y temperamento, Pedro Páramo es una novela que se parece a otra: las Cumbres Borrascosas de Emily Bronte. Es interesante compararlas porque ha habido una pugna necia en torno a la novela de Rulfo, una dicotomía que insiste en juzgarla sólo bajo la especie poética o sólo bajo la especia política, sin entender que la tensión de la novela está entre ambos polos, el mito y la épica, y entre dos duraciones: la duración de la pasión y la duración del interés.

Esto también es cierto de la obra de Emily Bronte, donde Heathcliff y Cathy pertenecen, simultáneamente y en tensión, a la duración pasional de la recuperación del paraíso erótico de la infancia y a la duración interesada de su posición social y su posesión monetaria. Georges Bataille ve en Cumbres Borrascosas la historia de la ruptura de una unidad poética y en seguida la de una rebelión de los expulsados del reino original, de los malditos poseídos por el deseo de recrear el paraíso. En cambio, el crítico marxista Arnold Kettle ve en la obra la historia de una transgresión revolucionaria de los valores morales de la burguesía mediante el empleo de las armas de la burguesía: Heathcliff humilla y arruina a los Lynton manipulando el dinero y la propiedad, los bienes raíces y las dotes matrimoniales.

Ambos tienen razón respecto a Bronte y la tendrían respecto a Rulfo. No son éstas novelas reducibles. La diferencia entre ambas es más interna y secreta: Heathcliff y Cathy están unidos por una pasión que se sabe destinada a la muerte. La sombría grandeza de Heathcliff está en que sabe que por más que degrade a la familia de Cathy, manipule y corrompa monetariamente a sus antiguos amos, el tiempo de la infancia compartida con Cathy-esa maravillosa instantaneidad - no regresará; Cathy también lo sabe y por ello, porque ella es Heathcliff, se adelanta a la única semejanza posible con la tierra perdida del instante: la tierra de la muerte. Cathy muere para decirle a Heathcliff: Este es nuestro hogar verdadero; reúnete aquí conmigo.

Susana San Juan hace sola este viaje y por ello su destino es más terrible que el de Catherine Earnshaw. No comparte con Pedro Páramo ni la infancia ni el erotismo ni la pasión ni el interés: Pedro Páramo ama a una mujer radicalmente separada de él, a un fantasma que, como Cathy, le precede a la tumba pero sólo porque Susana ya estaba muerta y Pedro no lo sabía. Y sin embargo, Pedro la amó, Pedro la soñó y porque la soñó y la amó es un ser vulnerable, frágil, digno a su vez de amor y no el cacique malvado, el villano de película muda, el conquistador de los muros de Pelacio, que pudo haber sido. Pedro le debe a Susana su herida; Susana le invita a reconocerse en la muerte.

La muerte, dice Bataille de Cumbres Borrascosas, es el origen disfrazado. Puesto que el regreso al tiempo instantáneo de la infancia es imposible, el loco amor sólo puede consumarse en el tiempo eterno e inmóvil de la muerte: un instante sin fin. El fin absoluto contiene en su abrazo todas las posibilidades 
del pasado, del presente, y del futuro. La infancia y la muerte son los signos del instante porque siendo instantáneos, sólo ellos pueden renunciar al cálculo del interés.

Infancia y muerte: ¿serán éstos los dos temas verdaderos de Pedro Páramo?, ¿se resuelven en esta cercanía las oposiciones entre mito y epopeya, el pasado idílico que recuerda Doloritas y la antigua desgracia que recuerda la Cuarraca, el mugido inarticulado de las vacas y las pesadas palabras que matan a Juan Preciado?

Rulfo, como Job en el sueño de la tumba, escribe una novela poemática donde no cabe hacer la distinción entre hypnos y tanatos, entre el sueño y la muerte. La educación de Juan Preciado, no una educación sentimental ni un bildungsroman, sino un totensroman, una novela para la muerte y un angsttraum, un sueño para el miedo, ha consistido en viajar hacia el origen para llegar al padre y descubrir que el padre es historia y la historia es injusta y que el padre, el jefe, el conquistador, debe morir para ingresar al eterno presente, que es la muerte.

En la muerte, retrospectivamente, sucede la totalidad de Pedro Páramo. De allí la estructura paralela y contigua de las historias: cada una de ellas es como una tumba; más bien: es una tumba, crujiente, mojada y vecina de todas las demás. Aquí, completada su educación en la tierra, su educación para la muerte y el terror, acaso Juan Preciado alargue la mano y encuentre, él sí, ahora sí, su propia pasión, su propio amor, su propio reconocimiento: acaso Juan Preciado, en el cementerio de Comala, acostado junto a ella, con ella, concozca y a me a Susana San Juan y sea a mado por ella, como su padre quiso y no pudo. Y quizás por esto Juan Preciado se convierte en fantasma para conocer y mirar a Susana San Juan en la tumba.

El destino entonces se habrá cumplido, fuera de las páginas del libro en cuyo centro el ganado muge, una limosnera arrulla un molote como si fuese un crío porque le sucedió una desgracia allá en sus tiempos y el silencio busca desesperadamente a la palabra. 
